In conclusion, we report patients with diverse neurological conditions presenting as airway reflux cough. This highlights the importance of a detailed history and examination in patients with apparently idiopathic cough.

\section{Pradeep S. Karur*, , Jaymin B. Morjaria ${ }^{*, \#}$, Caroline Wright* and Alyn H. Morice* \\ *Division of Cardiovascular and Respiratory Studies, Hull York Medical School, University of Hull, Castle Hill Hospital, Cottingham, UK. "Both authors contributed equally.}

Correspondence: P.S. Karur, Division of Cardiovascular and Respiratory Studies, Hull York Medical School, University of Hull, Castle Hill Hospital, Castle Street, Cottingham, HU16 5JQ, UK. E-mail: karurp@yahoo.co.uk

Statement of Interest: J.B. Morjaria has received honoraria for speaking and financial support to attend meetings from Chiesi, Pfizer, MSD, Boehringer Ingelheim and GSK. A.H. Morice has received honoraria for speaker meetings and financial support to attend meetings/advisory boards from Chiesi, Pfizer, MSD, Boehringer Ingelheim, Novartis, GSK, AstraZeneca, Proctor \& Gamble Healthcare, Orion Respiratory UK, Vectura Ltd, and Nycomed.

\section{REFERENCES}

1 Ford PA, Barnes PJ, Usmani OS. Chronic cough and Holmes-Adie syndrome. Lancet 2007; 369: 342.

2 Kimber J, Mitchell D, Mathias CJ. Chronic cough in the HolmesAdie syndrome: association in five cases with autonomic dysfunction. J Neurol Neurosurg Psychiatry 1998; 65: 583-586.

3 Spring PJ, Kok C, Nicholson GA, et al. Autosomal dominant hereditary sensory neuropathy with chronic cough and gastrooesophageal reflux: clinical features in two families linked to chromosome 3p22-p24. Brain 2005; 128: 2797-2810.

4 Jardine DL, Melton IC, Bennett SI, et al. Baroreceptor denervation presenting as part of a vagal mononeuropathy. Clin Auton Res 2000; 10: 69-75.

5 Morice AH, Faruqi S, Wright CE, et al. Cough hypersensitivity syndrome: a distinct clinical entity. Lung 2011; 189: 73-79.

6 Kinekawa F, Kubo F, Matsuda K, et al. [Gastroesophageal reflux disease in diabetic patients]. Nihon Rinsho 2004; 62: 1546-1552.

7 Kinekawa F, Kubo F, Matsuda K, et al. Relationship between esophageal dysfunction and neuropathy in diabetic patients. Am J Gastroenterol 2001; 96: 2026-2032.

8 Morice AH, Geppetti P. Cough. 5: The type 1 vanilloid receptor: a sensory receptor for cough. Thorax 2004; 59: 257-258.

9 Boeckxstaens GE. The lower oesophageal sphincter. Neurogastroenterol Motil 2005; 17: Suppl. 1, 13-21.

10 Dobrek L, Nowakowski M, Sygula A, et al. 24-hour heart rate variability in patients with gastroesophageal reflux disease. Folia Med Cracov 2005; 46: 53-64.

\title{
Treat-to-target approach in pulmonary arterial hypertension: a consensus-based proposal
}

\section{To the Editor:}

Goal-oriented therapy, also known as treat-to-target therapy, is recommended in the European Society of Cardiology (ESC)/ European Respiratory Society (ERS) guidelines for the diagnosis and treatment of pulmonary hypertension [1,2]. This approach, first described by HOEPER et al. [3], has emerged, alongside early detection, as a central aspect of managing pulmonary arterial hypertension (PAH). Goal-oriented therapy is proactive as it defines treatment goals ahead of time and proposes to alter the treatment strategy if those goals are not met.

In a review article on goal-oriented therapy in PAH by SITBON and GALIE [4], the authors noted that existing treatment goals are mainly based on parameters with prognostic value at baseline and highlighted the need for additional data to identify goals that have prognostic relevance during treatment. Subsequently, a single-centre study in 109 patients with idiopathic PAH has provided evidence to support the prognostic importance of achieving certain goals during therapy [5]. In this study, the following parameters were individually associated with improved prognosis when assessed at the first follow-up visit (3-12 months after initiation of PAH-specific therapy), supporting their use as treatment goals: 1) improvement to, or maintenance of, New York Heart Association/World Health Organization functional class (FC) I or II; 2) cardiac index $\geqslant 2.5 \mathrm{~L} \cdot \mathrm{min}^{-1} \cdot \mathrm{m}^{-2}$; 3) mixed venous oxygen saturation $\geqslant 65 \%$; or 4) N-terminal pro-brain natriuretic peptide (BNP) levels $<1,800 \mathrm{ng} \cdot \mathrm{L}^{-1}[5]$.

The review by SItBON and GALIE [4] also highlighted that combining baseline parameters may improve prediction of survival in PAH, and emphasised the need for multiple treatment goals. In a recent multicentre study of 226 consecutive patients with idiopathic or familial PAH, the combined use of baseline values for peak oxygen uptake and pulmonary vascular resistance (PVR) provided a more comprehensive prognostic assessment than either parameter alone [6]. Taking the concept a step further, two independent risk scores that combine multiple clinical parameters to predict prognosis have been developed $[7,8]$. In a recent single centre, retrospective study that independently validated the REVEAL (Registry to Evaluate Early and Long-Term PAH Disease Management) score [8], it was shown that assessment of the REVEAL prediction score in addition to FC enhanced prediction of 
Pulmonary Arterial Hypertension Treat-to-Target Checklist

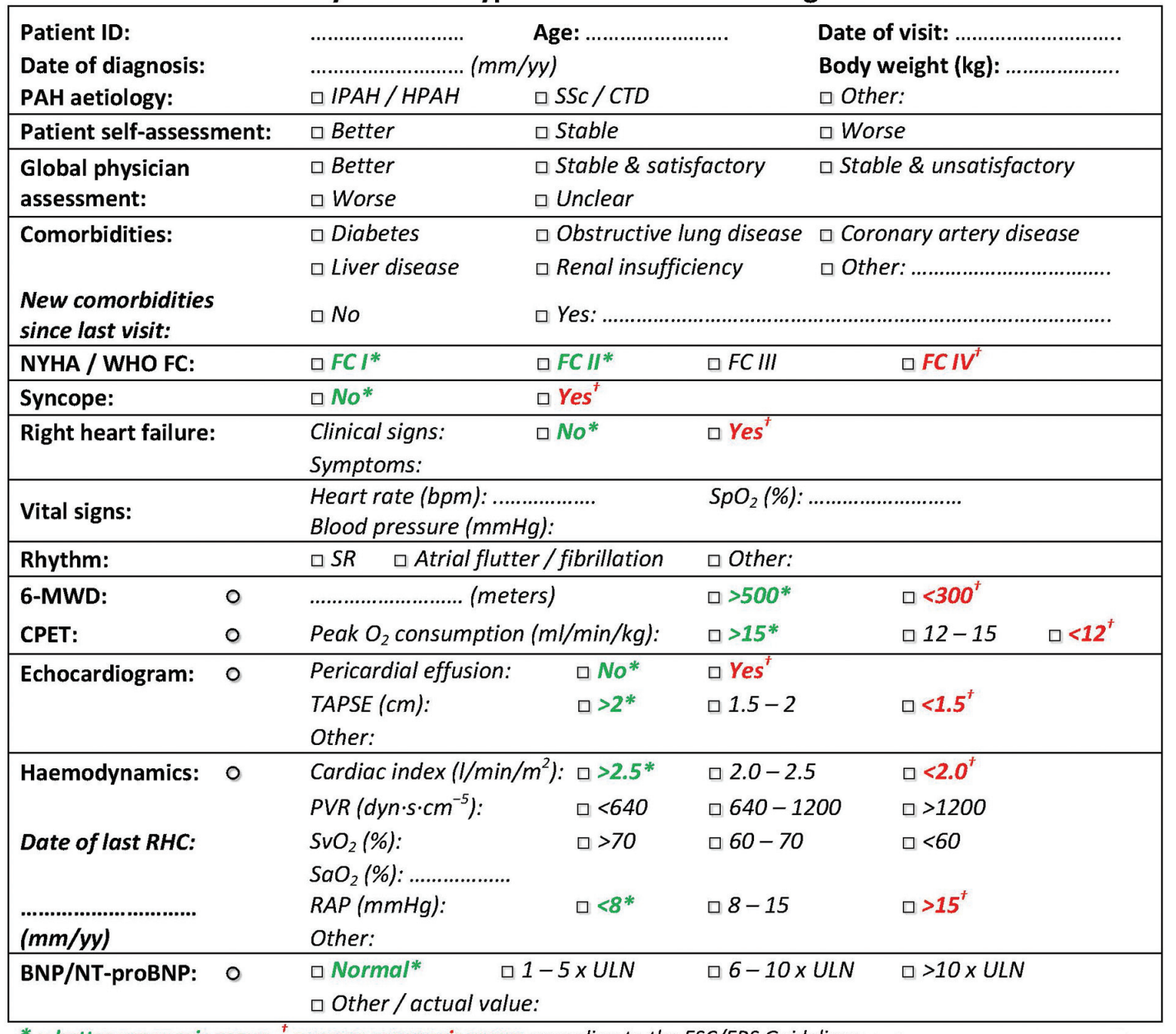

* = better prognosis group, ${ }^{+}=$worse prognosis group according to the ESC/ERS Guidelines

$\mathrm{O}=$ tick if exam not done at this visit

\section{Treatment Goals for this Patient}

1. Treatment goal is to reach or maintain: $\quad \square \mathrm{FC} / / \mathrm{II} \quad \square$ Other:

2. 6-MWD goal:

3. a.) Goal for haemodynamic parameters (incl. RHC):

b.) Goal for non-invasive parameters:

4. Follow up in: $\quad \square 3$ months $\quad \square 6$ months $\quad$ Follow-up date:

If treatment goals will not be reached at next visit, I plan to:

$\square$ Add PAH-specific therapy:

$\square$ Refer to another PAH centre, if appropriate

$\square$ Initiate palliative treatment

$\square$ Prepare for lung transplant

$\square$ Other:

5. Planned tests for next visit:

6. Patient expectations: 


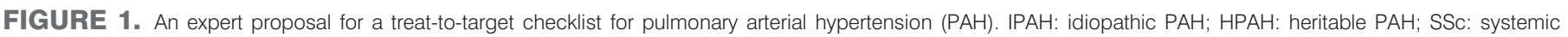

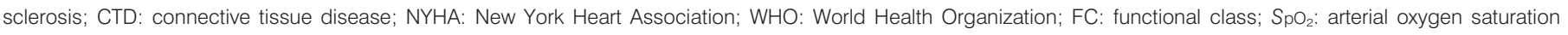

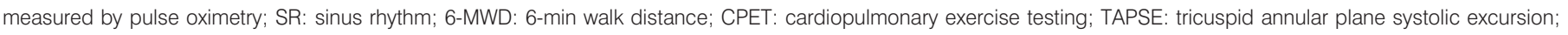

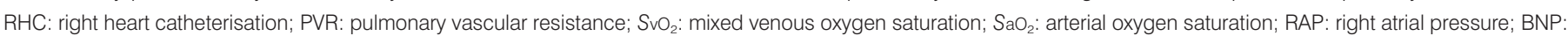
brain natriuretic peptide; NT-proBNP: N-terminal pro-BNP; ULN: upper limit of normal.

prognosis compared with FC alone [9]. These data have given us a better understanding of the importance of using multiple parameters when assessing prognosis, suggesting that there is a need to employ multiple treatment goals to monitor treatment response in $\mathrm{PAH}$ patients.

Implementation of goal-oriented therapy remains challenging despite the availability of new data and published guidelines. The application of generic guidelines to individual patients requires careful consideration of the $\mathrm{PAH}$ aetiology and comorbidities. The aim of treatment has evolved from achieving a "stable" condition for the patient to reaching a "stable and satisfactory" condition, which is defined in the ESC/ERS guidelines as fulfilling the majority of criteria indicative of better prognosis $[1,2]$. However, for patients that do not clearly meet the criteria for either better or worse prognosis (i.e. those that fall in the grey zone), it remains unclear if they are "stable and satisfactory" and, thus, it is difficult to determine the best treatment strategy. Although published case studies provide practical examples of using goal-oriented therapy in clinical practice [10, 11], additional guidance is needed.

An additional issue is that recommendations from the ESC/ ERS guidelines are not always followed in clinical practice. For example, intravenous epoprostenol is recommended in the guidelines as first-line therapy for patients in FC IV, due to its benefit on long-term outcomes [2]. Despite this recommendation, however, a recent study reported that $40 \%$ of FC IV patients were not receiving a parenteral prostanoid at the time of death [12]. Additionally, in some countries other barriers to implementing treat-to-target therapy may exist, such as lack of approval status and reimbursement for certain targeted therapies.

To define potential initiatives to support expert clinicians in implementing goal-oriented therapy in their daily clinical practice, an industry-sponsored Steering Committee for the Implementation of the Treat-to-Target Guidelines in PAH was recently formed. The Committee comprises of 11 members (including pulmonologists, cardiologists and a nurse specialist), who are experts in the field of $\mathrm{PAH}$, representing $11 \mathrm{PAH}$ centres from six European countries. A consensus-based checklist was developed (fig. 1) with the aim of providing a practical tool to assist clinicians in the application of goal-oriented therapy in individual $\mathrm{PAH}$ patients in a structured, consistent and prospective manner. It targets PAH-expert centres and the centres that they closely collaborate with.

The PAH treat-to-target checklist includes a section to document clinical assessment of the patient, at the time of treatment initiation and upon subsequent re-assessments. This is followed by a section to record the treatment goals set by the clinician that the patient should reach by the next visit (taking into consideration confounding and limiting factors, such as comorbidities or age) and allows clinicians to document the pre-determined schedule for re-assessment and action to be taken if the treatment goals are not met (e.g. switching or escalating therapy).

The Committee have developed this checklist to allow individualised treatment goals to be set, treatment response to be monitored and a clear and prospective treatment strategy to be developed for each patient. By setting individualised treatment goals, clinicians can keep track of the patient's response to therapy and can subsequently take appropriate action depending on the patient's response. The frequency of reassessment should follow the recommendations in the ESC/ ERS guidelines [1, 2].

Some of the parameters that are recommended in the ESC/ERS guidelines, which are reflected accordingly in the checklist, may carry more weight than others. This is dependent on factors such as clinician experience and differences in usual clinical practice. For example, in centres that do not perform frequent right heart catheterisation, noninvasive assessments such as echocardiography, cardiopulmonary exercise testing, $\mathrm{BNP}$ or N-terminal-proBNP levels and magnetic resonance imaging may play a more prominent role in the decisionmaking process.

The treat-to-target checklist represents the expert opinion of the Steering Committee and has not undergone formal validation. The checklist is intended to support the clinician in applying the ESC/ERS guidelines to each individual patient in their daily clinical practice. However, it cannot replace clinical judgement and the experience of an expert.

Olivier Sitbon ${ }^{*, \#, q}$, Adolfo Baloira Villar ${ }^{+}$, Fabrice Bauer $^{\xi, f}$, Björn Ekmehag**,\#\#, Wendy Gin-Sing ${ }^{\text {} ๘ \text {, Kjell Jansson }}{ }^{++, \S \S}$ David G. Kiely ${ }^{f f}$, Hanno Leuchte ${ }^{* * *}$, Alessandra Manes ${ }^{\# \#,}$ Stephan Rosenkranz ${ }^{\uparrow \uparrow \uparrow}$ and Pilar Escribano ${ }^{++, \S \S \S}$

*Université Paris-Sud, Faculté de Médecine, ${ }^{*}$ AP-HP, Centre de Référence de l'Hypertension Pulmonaire Sévère, Service de Pneumologie, CHU de Bicêtre, Le Kremlin-Bicêtre, "INSERM U999, IPSIT, Centre Chirurgical Marie-Lannelongue, Le Plessis-Robinson, ${ }^{\S}$ Centre de Compétences de l'Hypertension Pulmonaire, Service de Cardiologie, Pôle Thorax, Hôpital Charles-Nicolle, and ${ }^{f}$ Université de Rouen, Faculté de Médecine, INSERM 1096, Rouen, France. ${ }^{+}$Dept of Pneumology, Hospital Montecelo, Pontevedra, ${ }^{+++}$Pulmonary Hypertension Unit, Hospital Universitario 12 de Octubre,

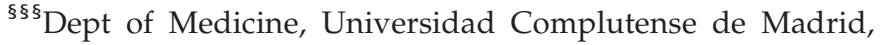
Madrid, Spain. ${ }^{* * N o r r t a ̈ l j e ~ H o s p i t a l, ~ N o r r t a ̈ l j e, ~ \# \# ~ D e p t ~ o f ~}$ Cardiology, Lund University, Lund, ${ }^{++}$Depts of Cardiology and Physiology, Linköping University Hospital, ${ }^{\S \S} \mathrm{IMH}$ Linköping University, Linköping, Sweden. "Dept of Cardiology, Hammersmith Hospital, London, ${ }^{f f}$ Sheffield 
Pulmonary Vascular Disease Unit, Royal Hallamshire Hospital, Sheffield, UK. ${ }^{* * *}$ Medical Dept II, Neuwittelsbach Hospital, Munich, ${ }^{\natural "}$ Klinik III für Innere Medizin, Universität

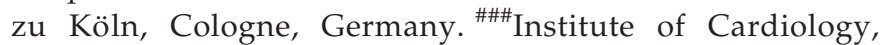
Università di Bologna, Bologna, Italy.

Correspondence: O. Sitbon, Service de Pneumologie, CHU de Bicêtre, 78 rue du General Leclerc, 94270 Le Kremlin-Bicêtre, France. E-mail: olivier.sitbon@bct.aphp.fr

Statement of Interest: O. Sitbon has relationships with pharmaceutical companies including Actelion, Bayer HealthCare, GSK, Lilly, Pfizer and United Therapeutics. In addition to being investigator in trials involving these companies, relationships include consultancy service, membership of scientific advisory boards, fees for speaking, funds for research and reimbursement for attending symposia. A. Baloira has received research grants from Actelion, has participated in meetings sponsored by Actelion, GSK, Bayer, Lilly and Pfizer, and has acted as an advisor for Pfizer, Lilly and GSK. F. Bauer has received reimbursement for attending a symposium from Actelion and Pfizer; has received a fee for speaking from Actelion, GSK and Servier; has received a fee for organising education from Bristol Myers Squibb, Daiichy-Sankyo, Lilly, Medtronic and GSK; has received fees for consulting from Pfizer and Actelion; and has acted as an expert witness on the subject of this study for Actelion. B. Ekmehag has received honoraria for serving as a consultant and/or speaker from Actelion, AstraZeneca, Bayer Schering, Lilly, NordicInfu Care, Pfizer and United Therapeutics. He has also received funds for a member of staff and/or funds for research from Actelion and NordicInfu Care. He has also conducted clinical trials supported by Actelion, Bayer Schering, GE HealthCare, GSK, Lilly, Novartis, Pfizer and United Therapeutics. W. Gin-Sing has received fees for speaking and consulting and funding to attend congresses from Bayer, Actelion, GSK, Lilly, Pfizer and United Therapeutics. K. Jansson has received honoraria for serving as a consultant and/or speaker from Actelion, AstraZeneca, Bayer, Lilly, Novartis and Pfizer. K. Jansson has been involved in conducting clinical trials supported by Actelion, Bayer, GSK, Lilly, Novartis and Pfizer. D.G. Kiely has received consultancy fees for giving educational lectures and participating in advisory boards, and has received funding to attend congresses from Actelion, Bayer, Pfizer, GSK, United Therapeutics and Lilly. Actelion, Bayer and Pfizer have provided unrestricted educational grants to fund clinical research fellows at the institution where D.G. Kiely is employed. H. Leuchte has served on the advisory boards of Actelion, GSK, Lilly and Pfizer, and has received lecture fees from Actelion, Bayer, GSK, Lilly and Pfizer and grant support from Actelion and MondoBiotech. A. Manes has received fees for speaking from Actelion, Pfizer, Lilly and GSK. S. Rosenkranz has received honoraria for serving as a consultant and/or speaker from Actavis, Actelion, AstraZeneca, Bayer, GSK, Lilly, Novartis, Pfizer and United Therapeutics, and has been involved in developing educational material for Actelion, Bayer, GSK, Novartis and Pfizer. The institution where S. Rosenkranz is employed has received unrestricted educational grants from Actelion, Bayer,
Novartis and Pfizer to fund research and clinical research fellows. S. Rosenkranz has been involved in conducting clinical trials supported by Actavis, Actelion, Bayer, GSK, Lilly, Novartis, Pfizer and United Therapeutics. P. Escribano has been a consultant for Actelion, GSK, Pfizer and Lilly. Her institution has received or has grants pending from Actelion, Bayer and Pfizer. She has received lecture fees from Actelion, Pfizer, Bayer and Lilly and has developed educational material for Pfizer and Actelion.

Provenance: Publication of this peer-reviewed article was supported by Actelion Pharmaceuticals Ltd, Switzerland (article sponsor, European Respiratory Review issue 125).

Acknowledgements: This project was developed and funded by Actelion Pharmaceuticals Ltd (Allschwil, Switzerland). Medical writing assistance was provided by R. Lloyd (nspm UK Ltd, Cheadle, UK), funded by Actelion Pharmaceuticals Ltd.

\section{REFERENCES}

1 Galiè N, Hoeper MM, Humbert M, et al. Guidelines for the diagnosis and treatment of pulmonary hypertension. Eur Respir J 2009; 34: 1219-1263.

2 Galiè N, Hoeper MM, Humbert M, et al. Guidelines for the diagnosis and treatment of pulmonary hypertension. Eur Heart $J$ 2009; 30: 2493-2537.

3 Hoeper MM, Markevych I, Spiekerkoetter E, et al. Goal-oriented treatment and combination therapy for pulmonary arterial hypertension. Eur Respir J 2005; 26: 858-863.

4 Sitbon $\mathrm{O}$, Galiè N. Treat-to-target strategies in pulmonary arterial hypertension: the importance of using multiple goals. Eur Respir Rev 2010; 19: 272-278.

5 Nickel N, Golpon H, Greer M, et al. The prognostic impact of follow-up assessments in patients with idiopathic pulmonary arterial hypertension. Eur Respir J 2012; 39: 589-596.

6 Wensel R, Francis DP, Meyer FJ, et al. Incremental prognostic value of cardiopulmonary exercise testing and resting haemodynamics in pulmonary arterial hypertension. Int J Cardiol 2012 [Epub ahead of print DOI:10.1016/j.ijcard.2012.03.123].

7 Humbert M, Sitbon O, Yaici A, et al. Survival in incident and prevalent cohorts of patients with pulmonary arterial hypertension. Eur Respir J 2010; 36: 549-555.

8 Benza RL, Miller DP, Gomberg-Maitland M, et al. Predicting survival in pulmonary arterial hypertension: insights from the Registry to Evaluate Early and Long-Term Pulmonary Arterial Hypertension Disease Management (REVEAL). Circulation 2010; 122: $164-172$.

9 Kane GC, Maradit-Kremers H, Slusser JP, et al. Integration of clinical and hemodynamic parameters in the prediction of longterm survival in patients with pulmonary arterial hypertension. Chest 2011; 139: 1285-1293.

10 Hoeper MM. "Treat-to-target" in pulmonary arterial hypertension and the use of extracorporeal membrane oxygenation as a bridge to transplantation. Eur Respir Rev 2011; 20: 297-300.

11 Sitbon O. Pulmonary arterial hypertension: combination therapy in the modern management era. Eur Respir Rev 2010; 19: 348-349.

12 Farber H, Miller D, Beery F, et al. Use of parenteral prostanoids at time of death in patients with pulmonary arterial hypertension enrolled in REVEAL. Chest 2011; 140: 903A. 